Stability and Change in Autobiographical Reasoning: A Four-Year Longitudinal Study of Narrative Identity Development

\author{
Kate C. McLean ${ }^{1}$ \\ David Dunlap ${ }^{1}$ \\ Sarah C. Jennings ${ }^{2}$ \\ Nicole S. Litvitskiy ${ }^{2}$ \\ Jennifer P. Lilgendahl ${ }^{2}$ \\ ${ }^{1}$ Western Washington University \\ ${ }^{2}$ Haverford College
}

(in press). Journal of Personality.

Author Note: We thank Moin Syed for being our statistical consultant on this project, and all around positive support person. We also thank student research assistants Lexi Lowe, Kristin Sarjeant, Samantha Boggs, Kristin Haraldsson, and Isabella Koepf who completed the self-event connection coding. We would also thank Nick Jones for his logistical and administrative support of the Identity Pathways Project (IPP), Benjamin Le, project co-PI, for ongoing methodological and conceptual input on the project, and the support of our respective institutions - Haverford College and Western Washington University - where IPP was conducted. We also thank Annie Fast, Antonya Gonzalez, and Annie Riggs for comments on an earlier draft of this manuscript. Finally, we thank our funding sources for IPP - Haverford College and a grant from the National Science Foundation, Award ID: 1528330. 
Link to OSF page for Identity Pathways Project: https://osf.io/57ax3/

\begin{abstract}
Objective. Research on personality development has traditionally focused on rank-order stability and mean-level change in the context of personality traits. The present study expands this approach to the examination of change and stability at another level of personality narrative identity - by focusing on autobiographical reasoning. Drawing from theory in personality and developmental science, we examine stability and change in exploratory processing and positive and negative self-event connections.
\end{abstract}

Method. We take advantage of a longitudinal study of emerging adult personality and identity development, which includes four waves of data across four years, examining reasoning in two domains of identity, academics and romance $(n=1520$ narratives; $n=176-638$ participants, depending on the analysis).

Results. We found moderate rank-order stability in autobiographical reasoning, but more so for exploratory processing than self-event connections. We found mean-level increases for exploratory processing in the context of romance, and stability in the context of academics. For self-event connections, we saw a decrease for positive connections, and for negative connections about romance, with stability for negative connections about academics.

Conclusions. Implications include developmental differences in types of reasoning, as well as the sensitivity of narrative identity to revealing the contextual nature of personality development.

Key Words: narrative identity, personality development, rank-order stability, mean-level change, emerging adulthood, autobiographical reasoning 


\section{Stability and Change in Autobiographical Reasoning: A Four-Year Longitudinal Study of Narrative Identity Development}

Contemporary research on narrative identity has broadened and deepened the conceptualization of personality, moving the field of personality towards a richer and more complex understanding of individual differences beyond traits (McAdams \& McLean, 2013; McAdams \& Pals, 2006; McLean, Syed, Pasupathi, Adler, Dunlop, Drustrup, Fivush, Graci, Lilgendahl, Lodi-Smith, McAdams, \& McCoy, 2019; Singer, 2004), and showcasing the critical role of narrative identity for well-being and psychological health (e.g., Adler, Lodi-Smith, Philippe, Houle, 2016). However, the study of narrative identity has been severely limited by the lack of longitudinal studies to examine development over time, particularly in regard to the stability and change in processes of autobiographical reasoning, or the ways in which individuals interpret and make meaning of past events (Habermas \& Bluck, 2000; Habermas \& Reese, 2015). Given that a cornerstone of personality development research has been the understanding that traits generally tend to follow patterns of rank-order stability (i.e., stability of individual differences) coupled with normative mean-level change over time (Caspi, Roberts \& Shiner, 2005), it is time to give this kind of attention to development at the narrative level of personality, a level of personality that is more sensitive to contextual and developmental change (McAdams \& Pals, 2006).

Although the origins of the contemporary iteration of narrative identity research lie within personality psychology (McAdams \& Pals, 2006), narrative identity is also strongly rooted in developmental psychology (e.g., McAdams \& Cox, 2010; Nelson \& Fivush, 2004; McLean, Pasupathi, \& Pals, 2007), fields which have different emphases. Broadly, the personality tradition emphasizes stability in individuals' core patterns of thinking, feeling, and 
behaving, whereas the developmental tradition emphasizes patterns of change, on which we elaborate below. Drawing from these two theoretical traditions, we ask whether there is meanlevel change stability in two types of autobiographical reasoning in the narration of different types of events, in a multi-wave four-year longitudinal study of emerging adult identity development in the college years (Lilgendahl \& McLean, 2019). There are only two studies of which we are aware that have examined change and stability in autobiographical reasoning over time, each with fewer assessment points than were collected in the current multi-wave study. (Dunlop, Guo, \& McAdams, 2016; McAdams, Bauer, Sakaeda, Anyidoho, Machado, MagrinoFailla, White, \& Pals, 2006). We detail these studies below.

\section{Narrative Identity and Autobiographical Reasoning}

The concept of narrative identity centers on the importance of integration in one's selfunderstanding, particularly through time (Pasupathi, Mansour, \& Brubaker, 2007; Syed \& McLean, 2016). That is, how do you know you are the same person through time, despite the ebbs and flows of behaviors, experiences, and ways of understanding oneself, others, and the world? Developing this sense of integration through time rests on the narration of important life experiences and the development of a broader life story that explains the linkages between such experiences and the self. For example, one might recall the story of one's parents (or one's own) divorce and how that event impacted one's own views on relationships. Such a reflective process, in the context of the narration of past events, is termed autobiographical reasoning (Habermas \& Bluck, 2000; Habermas \& Reese, 2015).

The extant research has shown that the complex process of reflecting on past events and narrating them in such a way as to explain who one is and how one has developed over time begins in late middle childhood and early adolescence (e.g., Habermas \& Reese, 2015). There 
are age-related increases in such reasoning across adolescence and emerging adulthood (e.g., Habermas \& de Silveira, 2008; McLean \& Breen, 2009; Reese, Chen, McAnally, Myftari, Neha, Wang, \& Jack, 2014), with some evidence of increases through mid-life (Pasupathi \& Mansour, 2006). It is important to note that these studies showing mean-level were cross-sectional rather than longitudinal; data are lacking on rank-order stability or intra-individual change, which require longitudinal designs to test.

Autobiographical reasoning processes are also clearly related to psychological adjustment in emerging adult and adult samples (e.g., Adler et al., 2016; see also Fivush, Booker, \& Graci, 2017; Lilgendahl, 2015). For example, in cross-sectional studies, those who are more reflective about the personal past and find meaning and positive resolution in particularly challenging events have higher well-being (e.g., Booker, Brakke, Sales, \& Fivush, 2021; Lilgendahl \& McAdams, 2011). In some of the few short-term longitudinal studies, we see that processes of autobiographical reasoning precede changes in mental health (Adler, 2012), and relate to increasing maturity over time (King \& Raspin, 2004; Pals, 2006), suggesting that such processes are a mechanism for pathways of development (see also McLean \& Pasupathi, 2012).

Despite the established importance of autobiographical reasoning to well-being and development, we know relatively little about whether such a process is a relatively stable part of a person, or whether it is a process evoked when needed - such as in the narration of a challenging and disruptive event that demands explanation, like familial divorce. Multi-wave longitudinal studies with different kinds of events are needed to answer these questions, and until now few such studies have existed. However, in making hypotheses about patterns of stability or change in processes of autobiographical reasoning there are at least two issues that need attention. The first is the type of autobiographical reasoning. There are many operational 
definitions of autobiographical reasoning (see Adler et al., 2016; McLean et al., 2019), and we chose to examine two of the more prominent ways of assessing autobiographical reasoning exploratory processing and self-event connections. The second concern is whether those predictions are rooted in theory from personality or developmental science, as the types of autobiographical reasoning we examined are differentially rooted in these traditions.

\section{Types of Autobiographical Reasoning and Theoretical Roots}

The term autobiographical reasoning is broad and there have been many ways that researchers have operationalized it for various projects and samples (Adler et al., 2016). Two of the most prominent operationalizations are self-event connections and exploratory processing, which are designed to capture different components of the process of autobiographical reasoning. Exploratory Processing captures the degree to which individuals are engaged in reflective processes of analyzing and exploring the meaning of past events with an eye toward incorporating a long-term sense of change into oneself (Pals, 2006). It is similar in concept and coding to accommodative processing, which has been associated with similar patterns of personality development over time (e.g., King, Scollon, Ramsey, \& Williams, 2000). Self-event Connections are explicit references to aspects of the self (e.g., traits, worldview, behaviors) that are linked in some way to the event being narrated (Pasupathi et al., 2007). In other words, exploratory processing can be thought of as the activity of reflection, and self-event connections can be thought of as the product of that reflection, although they do share some conceptual and empirical overlap (McLean et al., 2019). Additionally, self-event connections may be further divided into those that are positive and negative in meaning for the self, ${ }^{1}$ which could have implications for stability and change.

\footnotetext{
${ }^{1}$ Pasupathi et al. (2007) originally divided self-event connections in those about change in the self and those about stability in the self, but we do not examine those types of connections here.
} 
Despite the overlap, these two aspects of autobiographical reasoning come from markedly different theoretical roots. Pals (2006) developed the system for coding exploratory processing to understand individual differences in narrative processing. Pals was working under the assumption that such processing captures a characteristic manner of engaging with the narration of the past that has trait-like qualities as well as broad developmental fluctuations that pertain to overall identity and personality development over time. In contrast, to capture the more specific and contextualized development of temporal integration, Pasupathi et al. (2007) developed the concept of self-event connections, which may or may not actually be integrated into one's identity. Rather, self-event connections are thought to reflect the activity of narration as the key mechanism of development. They also argued that whether one makes a self-event connection in the narration of a past event, and what kind, would be more dependent on the event itself rather than the individual. Recent evidence supports the notion of intra-individual variability in aspects of narration, with the event and prompt mattering for the degree and type of autobiographical reasoning (McLean, Pasupathi, Fivush, Greenhoot, \& Wainryb,, 2016; see also Pasupathi, Greenhoot, Fivush, \& McLean, 2020).

In sum, although narration is presumed to be a far more contextual aspect of personality than traits (McAdams \& Pals, 2006), there is variability within the level of narration. Specific to this project, self-event connections are presumed to be more contextual, and exploratory processing is assumed to be relatively more characteristic of the person. To understand the critical process of developing an integrated narrative identity it is useful to understand whether there is stability and change in different types of autobiographical reasoning, and whether the type of event being narrated matters for stability and change.

\section{Assessing Change and Stability in Autobiographical Reasoning}


Understanding normative developmental change and stability in individual characteristics is a fundamental question for personality development. Traditional approaches to personality, focused on traits, emphasize the need for continuity over time to provide evidence that a given construct is indeed a part of personality (e.g., Costa \& McCrae, 1994). Such approaches emphasize the importance of rank-order stability. That is, if one is at the highest level of conscientiousness in a given sample at Time 1 and maintains their rank in that sample at Time 2, there is evidence for stability in conscientiousness. In a study of trait stability over the college years, researchers found evidence of meaningful rank-order stability in personality traits ( $r$ 's $=.5$ - .7, depending on the trait; Robins, Fraley, Roberts, \& Trzesniewski, 2001).

However, personality develops in context and we would also expect to see some normative developmental change in personality traits (e.g., Roberts, 2007). According to Roberts' neo-socioanalytic model (e.g., Roberts \& Wood, 2006), along with rank-order stability we would expect to see mean-level changes in traits in response to social and contextual demands. For example, there is good evidence that over there are mean-level increases in conscientiousness in young adulthood (Roberts, Walton, \& Viechtbauer, 2006), perhaps in response to increased demands for responsibility and autonomous functioning that comes with common experiences at this developmental stage (e.g., work, school, managing finances, committed relationships).

Thus, there is a long history of looking at rank-order stability and mean-level change in traits, and the well-established pattern that is characteristic of traits is high levels of rank-order stability coupled with normative patterns of mean-level change. Yet despite the centrality of narrative identity to personality, there has been very little attention to such questions for stability and change in autobiographical reasoning. Two longitudinal studies, one in college students and 
one in midlife adults (McAdams, et al., 2006; Dunlop et al., 2016), offer some initial findings this area. In terms of rank-order stability, both studies demonstrated low to moderate rank-order stability ( $r$ 's ranging from .3 to .4 ) in narrative constructs that have some conceptual overlap with autobiographical reasoning (i.e., personal growth, redemption). However, in a recent study with adolescents, researchers found quite low rank-order stability for self-event connections or redemption across three waves of data one year apart, although the researchers acknowledge that their analyses were underpowered (de Moor, Van der Graaff, van Doeselaar, Klimstra, T.A., Branje, 2021). In terms of mean-level change, patterns at two time points from the beginning to end of college suggest an increase in autobiographical reasoning (McAdams et al., 2006). There was no general mean-level change over three years in the midlife sample, but those who lost their jobs in between the two measurement points decreased in redemption over time (Dunlop et al., 2016), suggesting the importance of developmentally contextualized events in examining patterns of stability and change in narration.

The current study was able to build on this work with several methodological advances. Most importantly, the study on college students was anchored in the beginning and end of college, resulting in a limited assessment in the course of change over this important developmental period. In the current study, we assessed narration at each year of college, allowing for the observation of non-linear effects and a fuller picture of narration throughout the college years. Further, recent evidence is showing that the topic or prompt of narration may matter for how an event is narrated (McLean et al. 2016; Pasupathi et al., 2020). Indeed, the finding that job loss was associated with decreasing redemption in midlife adults points to the importance of specific events and developmental contextualization for assessing stability and change in narrative. As we describe below, this project was designed as a developmentally 
contextualized examination of personality development in the college years. Thus, narrative assessments were tailored to the contexts that are likely to be developmentally significant in most college students' lives and identities - academics and romance (Lilgendahl \& McLean, 2019) and our design allowed us to examine whether narrative domain matters for stability and change in autobiographical reasoning.

\section{Present Study}

The current study utilized data from the Identity Pathways Project, a narrative-intensive longitudinal study of college students from two campuses in the United States (Lilgendahl \& McLean, 2019). In this study we are examining a broad array of aspects of personality and identity development, such as well-being and the transition to college (Lilgendahl \& McLean, 2019), under-represented minorities' persistence and desistence in STEM majors (McLean, Koepf, \& Lilgendahl, 2021), aspects of repeated narration (Patterson Dunlap, Payne, Peterson, Tiemersma, Turner, Wolin, Lilgendahl, \& McLean, 2021), and over-involvement of parents and success in college (Lilgendahl, DuSold, Lee, Prinz, \& McLean, 2021).

An examination of identity and personality development during the college years has some specific advantages, as this is a time of exploration, decision-making, and both change and integration of one's self. For example, the demands of developing new intimate relationships with peers, while at the same time maintaining and deepening relationships with family who are often more geographically distant can pose a challenge and an opportunity to understanding the self in relation to others. The demands of exploring academic pathways, major choice, and job and career options also provide opportunities for thinking about oneself in various contexts. Although these demands are representative of the college experience for many (Baxter Magolda, 2008), institutions vary in how well they support students in these endeavors (Baxter Magolda, 
2001), making individual differences in identity and personality development a prime question for this population.

Narratives utilized in the present examination consisted of academic and romantic high and low point experiences ( 4 narratives per time point; up to 16 narratives per person total) from the Spring of each of the four years of data collection. We examined rank-order stability for exploratory processing, positive self-event connections, and negative self-event connections, as well as whether there was mean-level change in these three aspects of autobiographical reasoning. For example, are those who reflect the highest levels of exploratory processing at Time 1 also those who reflect the highest levels of exploratory processing at Time 2 , and is there change in exploratory reasoning across the sample over time? We examined this change and stability at 4 time points (one year apart), in the narration of academic and romantic events.

In terms of our approach, we examined these aspects of autobiographical reasoning collapsed across all narratives, as well as separately for narratives about romance and academics. We had no hypotheses about change and stability in autobiographical reasoning within these domains, but given recent evidence that type of narrative may matter for narration (e.g., McLean et al., 2019; Pasupathi et al., 2020), we explored whether domain mattered.

In terms of our hypotheses about stability and change in autobiographical reasoning, this is a longitudinal study that creates some complexities for pre-registration. We detail our process for the present investigation in our pre-registration materials: https://osf.io/57ax3/. Briefly, we conducted an initial analysis of only the first cohort of the project (the second cohort was not yet complete with data collection). Our pre-registration is based on our analysis of that first cohort, before we examined any data from the second cohort. We expected moderate rank-order stability in all aspects of autobiographical reasoning, though more so for exploratory processing 
than positive or negative self-event connections, and we expected rank-order stability to increase over time. Our initial hypotheses were to expect increases in exploratory reasoning and positive self-event connections, but analyses of the first cohort did not support that. Thus, in our preregistration, we expected no mean-level change in exploratory processing or positive self-event connections, and had no hypotheses about negative self-event connections or about the role of domain.

\section{Method}

Each of the samples were collected under IRB approval at the following institutions: Campus 1: Haverford College (proposal entitled, “The Identity Pathways Project -- A Longitudinal Study of Narrative Identity Processes, Contexts, and Outcomes During College"); Campus 2: Western Washington University (14-038: Identity Pathways Project). Participants and Procedure

Participants were drawn from the Identity Pathways Project (IPP), an ongoing longitudinal study of college student development involving students from two institutions, a small, private, highly selective liberal arts college in the Northeastern United States (Campus 1) and a medium-sized, public, moderately selective state university in the Northwestern region of the United States (Campus 2). The general design of IPP is a multi-wave online survey study in which participants are surveyed in the summer before college begins (Wave 1), two more times during freshman year, Winter (Wave 2) and Spring (Wave 3), three times a year for each year of college after that, Fall, Winter, and Spring (Waves 4-12), and a one-year post-graduation followup (Wave 13). The current analyses involved data from Waves 3, 6, 9, and 12.

The samples at each institution were recruited over the summers to complete Wave 1 prior to starting college in a staggered fashion (recruited between 2013 - 2015), with an aim of 
recruiting approximately 300 participants per campus. The target sample size (300 from each campus) was largely determined by funding and logistical constraints, given that we paid participants \$20-25 per survey (with a total of 13 surveys over 5 years for the full study design), and extensive narrative data was collected at each survey that requires narrative coding.

For Campus 1, all members of the entering classes of 2013 and 2015 were invited to participate in IPP. In the Summer of $2013,48 \%(N=159)$ of the entering class participated. In the Summer of $2015,45 \%(N=157)$ of the entering class participating. For Campus 2 , there were approximately 3000 students in the two entering classes from which we recruited for this study (2014 and 2015). Every student who went to the summer orientation event $(90 \%$ attendance rate) received a flyer about the Identity Pathways Project. After that event, recruitment proceeded via email. In the Summer of 2014, a randomly selected sample of 400 students (gender balanced) from the entering class were sent an invitation to participate in the study via email. Once 150 people completed the survey, we stopped recruiting participants. A similar procedure was used in the summer of 2015, except that an attempt was made to oversample underrepresented students interested in STEM fields (for project goals not pertaining to this paper; McLean et al., 2021). An email invitation was sent to 500 students, which was a combination of randomly selected students, and non-Asian ethnic/racial minority students who expressed interest in STEM. This resulted in 173 participants from this class. In sum, across the two campuses, a total of 638 participants completed the Wave 1 survey in the summer prior to college ( $n=315$ for Campus 1 and $n=323$ for Campus 2).

For the full Wave 1 sample, $35 \%(n=221)$ identified as male and $63 \%(n=405)$ identified as female (eight wrote in alternative responses for gender and five were missing). For race/ethnicity, participants were allowed to select all applicable response options and report their 
own response if needed; $75 \%$ selected white, $6 \%$ selected Black/African-American, 10\% selected Latino/a, 18\% selected Asian, 2\% selected Native American, and 1\% selected "other". Additionally, 13\% selected more than one racial category. Although this overall pattern was quite similar across campuses, there were significant differences in the proportions selecting white (Campus $1=69 \%$, Campus $2=80 \%$ ) and Black/African-American $($ Campus $1=9 \%$, Campus $2=3 \%$ ). This pattern is generally consistent with both institutional and regional demographic differences between the two campuses.

Socioeconomic status (SES) was assessed with household income and father/mother educational level. Consistent with institutional differences, the campuses differed on indicators of SES. Household income was assessed with nine categories, with $1=$ less than $\$ 10,000$ a year to $9=$ over $\$ 200,000$ a year. The mode for both campuses was $\$ 90,000-\$ 120,000$ and the range for both campuses was 1-9; however, for Campus $1,43 \%$ fell below $\$ 90,000$ and $36 \%$ fell above $\$ 120,000$, whereas for Campus 2, 60\% fell below $\$ 90,000$ and $21 \%$ fell above $\$ 120,000$.

Further, the most extreme disparity was in the highest category of over $\$ 200,000$, with $20 \%$ for Campus 1 and 5\% for Campus 2. For Campus 1, 45\% of mothers had a master's degree or higher, 33\% had a 4 -year college degree, and $21 \%$ had some college or less. Similarly, $52 \%$ of fathers had a master's degree or higher, $23 \%$ had a 4 -year college degree, and $22 \%$ had some college or less. In contrast, for Campus 2, 22\% of mothers had a master's degree or higher, 26\% had a 4-year college degree, and a 53\% had some college or less. Similarly, $22 \%$ of fathers had a master's degree or higher, $28 \%$ had a 4-year college degree, and 50\% had some college or less.

For rank-order analyses, we include all participants who have at least two waves of data $(n=426)^{2}$. However, sample size varies for each particular correlation because participants

\footnotetext{
${ }^{2}$ This is a deviation from our pre-registration. We originally planned to include participants who have at least two adjacent waves, and we revised to include participants who had at least two waves of data to maximize our $\mathrm{N}$.
} 
dropped out, missed some waves, or did not respond to all narratives. For mean-level analyses, we used full information maximum likelihood when fitting multi-level models, and thus included all participants with at least one data point $(n=638)$.

We conducted three different types of analyses to test for attrition differences in campus, gender (male v. female, as only eight participants reported a gender identity outside the binary), ethnicity (white v. non-white, given sample sizes), SES (z-score of three indicators - household income, maternal education, paternal education), and conscientiousness.

First, we examined differences between participants who dropped out after Wave 1, versus those who completed at least one other wave (our least stringent attrition test). Those who identified as male were more likely to drop out after Wave 1 than those who identified as female, $X^{2}(1)=6.59, p=01(A S R=.07)$. Those lower on conscientiousness were more likely to drop out than those higher on conscientiousness, $t(636)=2.41, p=.01$. There were no differences for ethnicity $\left(X^{2}(1)=.16, p=.80\right)$, campus $\left(X^{2}(1)=2.41 p=.14\right)$, or SES $(t(635)=$ $.01, p=.99)$.

Second, we examined associations between these variables in terms of how many waves participants completed. Those who identified as women were more likely to complete more waves compared to those who identified as men, $t(623)=-2.68, p=.01$. Those with higher family SES were more likely to complete more waves than those with lower SES, $r(637)=.09, p$ $=.03$. Those at Campus 1 were more likely to complete more waves than those at Campus 2 , $t(636)=5.25, p=.00$. Those higher on conscientiousness were more likely to complete more waves than those lower on conscientiousness, $r(638)=.12, p=.01$. There were no differences for ethnicity, $t(634)=.70, p=.50$. 
Third, we examined differences between participants who completed at least one wave in the final year (wave 10,11, or 12), versus those who completed wave 1 plus one other wave (29) (our most stringent attrition test). Those at Campus 2 were marginally more likely to have completed at least one wave in the final year compared to those at Campus $1, X^{2}(1)=2.41, p=$ .07. Those with higher SES were marginally more likely to have completed at least one wave in the final year compared to those with lower SES, $t(543)=-1.97, p=.05$. There were no differences for gender $\left(X^{2}(1)=.36, p=.55\right)$, ethnicity $\left(X^{2}(1)=.10, p=.83\right)$, or conscientiousness $t(543)=-1.56, p=.12$.

These results are not entirely consistent across type of analysis, but it appears that there is a bit more attrition for men, and for those lower on conscientiousness and SES. We have no a priori reason to think that these variables will impact rank-order stability or mean-level change, so we do not include them as covariates, but report them here for transparency and generalizability.

\section{Narrative Coding}

Narrative prompts. Four narratives collected at Wave 3 - an academic high point and low point and a romantic high point and low point (all narrative prompts and coding systems can be found at OSF (https://osf.io/57ax3/). As can be seen in those Tables 1 - 9, there were fewer narratives reported for the romantic domain. Some participants had not had experiences in romantic relationships within the past year, and chose not to report a narrative.

Overall Coding Practices in the Project. For both coding systems described below, several teams of trained coders completed the coding over the course of data collection. In each successive year, training was completed on previously coded narratives in order to establish reliability within the coding team and to calibrate the coding to previously completed sets. After 
the initial round of training, a subset of the primary narratives were coded independently and reliability was checked and further discussion took place when needed (Syed \& Nelson, 2015). Coding of Exploratory Processing. Adapted from Pals (2006), exploratory processing was rated on a four-point continuous scale. A narrative receiving a one was concrete and matterof-fact in the description of the past event with little to no evidence of reflection or consideration of the broader meaning or impact of the event on the self or one's life. In contrast, a rating of four was assigned when exploratory processing was a pronounced and central theme of the narrative, with elaborated in-depth reflection on the potentially transformative meaning and impact of the event. For reliability, ICCs were calculated for each narrative type at each wave (e.g., academic high points at Wave 6), which ranged from .61 to 1.00 (92\% over .70).

Discrepancies were discussed throughout the coding process in order to minimize coder drift, and the final codes were calculated by averaging the coders' ratings together.

Coding of Self-event Connections. Self-event connections capture specific and explicit connections between the event described and the narrator's self (Pasupathi et al., 2007) that are positive (e.g., I have always been a kind person - stable positive), or negative (e.g., I became much more jealous in relationships after that experience - change negative), or about aspects of self that have changed, or have remained stable, though we do not include that kind of analysis here. Thus, self-event connections were identified in each narrative, and coded as stable or change, and positive or negative, resulting in frequencies for each of the following types of connections for each narrative: positive stable, negative stable, positive change, negative change $^{3}$. Note that the coding was not mutually exclusive; a single narrative could have any

\footnotetext{
${ }^{3}$ For the present analyses we do not examine change and stability connections.
} 
combination of these different types of connections, including a mix of positive and negative connections. Once reliability was reached, two coders continued to code all narratives.

Disagreements were settled by consensus between the two coders, or the PI if necessary (though this was quite rare). Reliabilities were acceptable for each type of connection (range $=.73-1.00$ across the four narrative prompts at each of the four years). Kappas could not be computed for some categories because of low base rates (e.g., negative connections in high points). For those, percent agreement ranged from 97\% - 100\%.

\section{Composite narrative variables}

Tables $1-9$ show the descriptives for all narrative variables. We scored up to a total of 36 narrative variables - nine at each of the four waves - and 1520 narratives. At each wave, we scored an overall composite as well as two separate domain-specific composites (academic and romantic) for each of the three forms of autobiographical reasoning. For exploratory processing, we averaged each person's score on exploratory processing across all four narratives (or as many narratives as they reported if less than 4), to create an overall composite. We also created domain-specific average scores by averaging across the academic (high and low point) and romantic (high and low point) narratives.

For self-event connections, we first summed the total number of positive self-event connections a person had for each narrative at each wave, and likewise for negative self-event connections. We then averaged those sums at each wave, dividing by the total number of narratives the person had, thus creating an average number of positive and negative self-event connections at each wave for each person. We repeated this process at each wave separately for each domain, creating average levels of positive and negative self-event connections in academic narratives and romantic narratives. 
The decision to use average scores rather than sums for the self-event connections represents a deviation from our original pre-registration for this project. Self-event connections are discrete units identified within the narrative and lend themselves to summing. However, we came to the realization, after pre-registration, that because participants did not all provide the same number of narratives at each wave (range: 1-4), an average score would be more comparable across people and across waves. Importantly, the results were the same regardless of whether we used sums or averages. We report the summed results in our supplemental files (https://osf.io/xvk5s/?view_only=5b035868b3b04f81aaa7abcdfe 7807f0).

The narrative variables showed a varying but generally substantial amount of skew. For self-event connections, skewness ranged from $1.42-7.48$, with all of the self-event connections variables showing a skewness statistic over 1. Kurtosis ranged from 1.69 to 79.5. For exploratory processing, skewness ranged from .75 to 1.35 , with four of 12 variable showing a skewness statistic over 1. Kurtosis ranged from -.25 to 1.64. To be consistent across all of these variables, we created and used logtransformed versions of the narrative variables for the stability and change analyses. Logtransformed variables for exploratory processing ranged from .18 - .50 for skewness, and -1.11 - -.50 for kurtosis. Logtransformed variables for self-event connections ranged from $.95-3.94$ for skewness, and $-.28-22.35$ for kurtosis. Given that self-event connections continue to be skewed, we report Spearman Rho's alongside Pearson correlations for the rank-order analyses. The averages reported in the first column of Tables 4-9 are the raw averages prior to log transformation; the results reported for rank-order stability and mean-level change use the logtransformed versions of the variables.

Results

Rank-Order Stability 
Exploratory Processing. Tables $1-3$ show the bivariate correlations between the composite exploratory processing (Table 1), as well as for academic (Table 2), and romantic (Table 3) narratives. There is significant rank-order stability in the composite variables with $r$ 's ranging from $.4-.5$. When breaking down the narratives by domain, there is still significant rank-order stability, but there is slightly more variability: $r$ 's range from $.3 .-.5$ for academic narratives, and from $.2-.4$ for romantic narratives.

Positive Self-event Connections. Tables $4-6$ show the bivariate correlations between the composite positive self-event connections variables (Table 4), as well as academic (Table 5), and romantic (Table 6) narratives. Though lower than the coefficients for exploratory processing, there is rank-order stability for self-event connections overall $(r$ 's $=.20$, with less consistency for academic narratives $(r$ 's range from $.11-.2)$ and romantic $(r$ 's range from -.02 - .2).

Negative Self-event Connections. Tables $7-9$ show the bivariate correlations between the composite negative self-event connections variables (Table 7), as well as academic (Table 8), and romantic (Table 9) narratives. The results here paint a less consistent picture, with $r$ 's ranging from -.05-.2 across all three analyses.

We include one additional analysis that was a deviation from our pre-registered hypotheses. Given the differences in rank-order stability for the different types of autobiographical reasoning, and recent suggestions that there may be more variability accounted for by domain than by person, particularly for autobiographical reasoning processes (e.g., McLean et al., 2016; Pasupathi et al., 2020), we examined intraclass correlations for the three types of autobiographical reasoning (composite variables). We found greater variability accounted for by the person for exploratory processing $(I C C=.46)$ compared to positive selfevent connects $(I C C=.16)$, and negative self-event connections $(I C C=.14)$. 


\section{Mean-Level Change}

In a deviation from our pre-registration, we did not use repeated measures ANOVAs to examine mean-level change. This was due to a reviewer suggestion to employ analyses that allowed us utilize more of the data that would have been missing in the ANOVAs. We do report the ANOVA analyses on our OSF site (https://osf.io/xvk5s/?view_only=5b035868b3b04f81aaa7abcdfe7807f0).

To examine mean-level change, we conducted a series of multi-level models for each construct. For each model, domain (romantic or academic) was nested within wave $(3,6,9,12)$, which in turn was nested within individuals. We examined linear and quadratic change models, but in all cases the Bayesian Information Criterion (BIC, a measure of model fit that accounts for model complexity) favored the linear model over the quadratic. The focus of the models was on the fixed effects of wave, domain, and the wave $\mathrm{X}$ domain interaction.

For exploratory processing, mean levels increased linearly across the study period $(b=$ $.02, S E=.007, p=.002)$ and processing was higher in academic vs. romantic narratives $(b=.11$, $S E=.03, p<.001)$. Additionally, there was a significant wave $\mathrm{X}$ domain interaction $(b=-.02$, $S E=.01, p=.03)$ indicating that exploratory processing in the romantic domain increased over time whereas the academic domain remained stable (Figure 1).

For positive self-event connections, we saw a linear decrease in connections over time $(b$ $=-.02, S E=.006, p<.001)$, and a main effect of domain $(b=.12, S E=.02, p<.001)$ with more positive connections in academic than romantic narratives (Figure 2). The wave $\mathrm{X}$ domain interaction was not significant.

For negative self-event connections, we saw a linear decrease in connections over time $(b$ $=-.02, S E=.004, p<.001)$, and no effect of domain $(b=-.03, S E=.02, p=.06)$. There was, 
however, a significant interaction $(b=.02, S E=.006, p=.003)$, indicating that connections in the romantic domain decreased over time, whereas those in the academic domain remained stable (Figure 3).

\section{Discussion}

As expected, we found evidence for rank-order stability in autobiographical reasoning and more so for exploratory processing than self-event connections, suggesting that type of autobiographical reasoning matters for rank-order stability over time. This was further supported with our unplanned analyses, showing greater variability due to the event than the person for self-event connections compared to exploratory processing. In terms of mean-level patterns for exploratory processing, we found stable and higher levels of reasoning about academics, and an increase in reasoning about romance over time. For self-event connections, we saw decreasing reasoning for positive connections over time, regardless of domain, decreasing negative connections for romance over time, and stability in negative connections about academics over tume, although we note that the base rates of negative connections were quite low. Finally, we generally saw more reasoning about academics than romance across types of reasoning. Below we address the meaning of these findings for the study of narrative identity development over time.

\section{Stability in Autobiographical Reasoning}

As expected, we found moderate rank-order stability for exploratory processing at the composite and domain level, with increasing rank-order stability over time. Our coefficients are similar to prior work on the rank-order stability of other components of narration (e.g., Dunlop et al., 2016; McAdams et al., 2006), and similar to or slightly lower than the kind of rank-order stability we see in personality traits in college students (Robins et al., 2001). In contrast, 
although there were significant rank-order stability coefficients for self-event connections, these were lower than for exploratory processing, and were even lower when looking at coefficients by domain. Finally, in an unplanned analysis, we found greater variability attributable to the person than the event for exploratory processing compared to self-event connections.

In thinking about one of the critical implications of these results, we reflected on one of the questions we are most often asked: which coding system or construct should I use? Of course, the answer to that depends on the research question, but these data provide some new information. These empirical findings support the theoretical roots of the two constructs, with exploratory processing designed to capture characteristic ways of narration, and self-event connections designed to be sensitive to development and context - that is, change. Thus, For those interested in more stable aspects of personality at the level of narrative, exploratory processing may be more useful. In contrast, for researchers interested in investigating change and development, or the sensitivity of narration to context, self-event connections may be a better bet. Self-event connections may also be more useful for tracking patterns of intra-individual differences in change. For example, two students may show equally low levels of positive selfevent connections early on, as they struggle to find their footing in college. However, they may then show distinct developmental trajectories - increasing in positive self-event connections over time and the other remaining low, for example. The presence of these two patterns in the same sample would bring down rank-order stability because their rank ordering is changing. However, these both are meaningful patterns of development that could only be identified by studying intra-individual variability in change.

\section{Change in Autobiographical Reasoning}


In terms of our mean-level results, for exploratory processing we found an increase over time, but only in the romantic domain, whereas exploratory processing was stable and higher across time for the academic domain. We saw a decreasing effect of time for positive self-event connections, stability in negative connections about academics, and a decreasing effect of time for negative connections in the romantic domain. We note that for the results on negative connections, in particular, they are problematized by their very low base rate, which may preclude a full understanding their developmental movement. We offer interpretations here of these findings here, and note the strong need for replication of these effects.

In terms of exploratory processing it appears that reasoning about academics is relatively stable. Indeed, academics are a relative constant over the course of college and there may already be a somewhat well-formed academic self-concept at entry into college. However, reasoning about romance showed a different pattern. For exploratory processing we saw an increase in reasoning, perhaps reflecting the salience of exploring oneself in the romantic domain as the focus on intimacy becomes a salient part of identity development for college-going emerging adults.

Although though there was a decrease in connections, overall, what we see as the more salient finding is that there were more positive than negative connections, which is consistent with recent theoretical arguments about the importance of positive autobiographical reasoning in emerging adulthood (Lilgendahl, 2015). It is also possible that positive self-event connections may be a more common and stable form of autobiographical reasoning than negative connections in relatively healthy samples, in the form of self-enhancement and the defense against the enduring effects of difficult events. We also saw more positive connections in reasoning academics than romance. It is possible that the narration of romance in for college-going 
emerging adulthood reflects more ups and downs with the ending and starting of relationships. Romance may also be more variable and idiosyncratic across individuals. College involves an emphasis on and attention to academics for everyone. But, for some, romance may not be as central or salient.

\section{Limitations and Conclusions}

First, we note that we used the same narrative prompts at each assessment, which may have led to decreased engagement for participants, perhaps lessening the degree of autobiographical reasoning. Of course, in longitudinal work there is a push and pull between asking questions attuned to specific aspects of current experiences, and desire to have comparable assessments across time. We also note the variable number of narratives per person per wave. This is due in part to attrition and whether or not participants had romantic experiences to write about. Further, recent unpublished data from Campus 1 suggests that there are a variety of important experiences for college students, beyond romance and academics, perhaps particularly for students from marginalized and minoritized backgrounds (Jennings, Cruz Navas, Dalsimer, Radin \& Lilgendahl, 2021). Finally, although an analysis of normative development is important to building theory and empirical understanding within a field, the nuances get lost, nuances that may best be captured in mixed-methods and qualitative work, or work focused on specific groups or populations that may not be represented in our "normative" analyses (see also McLean \& Riggs, 2021). Indeed, some of the most well-established relations between autobiographical reasoning and well-being are shown to be different and much more complex when examined with populations not included in the initial studies (e.g., McLean, Wood, \& Breen, 2013; Sales, Merrill, \& Fivush, 2013). 
We also note that we were intentional in designing a highly contextualized study of personality development during the college years, but this may have impacted our findings on stability and change. That is, we asked for highly contextualized narratives - contextualized by domain and time, as they occurred within the last year - which are quite different than the broad life story prompts used in prior studies (Dunlop et al., 2016; McAdams et al., 2006). Tthe same events can be repeated with those broader life story prompts, which might pull for stability, compared to our approach, which might pull for change.

It is also the case that autobiographical reasoning is only one way to examine stability and change in narration. We chose this construct because it is at the heart of the activity of developing one's identity (e.g., Habermas \& Reese, 2015). However, other aspects of narration may be more or less stable. For example, in a longitudinal study of adult participants, Waters, Camia, Raby, and Habermas (2019) found moderate correlations across two time points four years apart in the coherence of life narratives. Similarly, McLean et al. (2016) found that intraindividual variability was lowest for assessments of coherence compared to other aspects of narration like resolution, suggesting that coherence may be a place to find more stability over time and within persons.

Finally, we want to highlight the complexity of operationalizing stability and change at the level of narrative. We took an analytic approach rooted in work on traits, but narratives are a different beast. Indeed a recent special issue in Qualitative Psychology (see Adler, 2019 for an overview of the issue) addressed this question specifically. There are at least two ways to think about stability and change in narrative. The first, is the actual content of stories - does one tell the same story over time, or does the story change, such as in the response to a prompt for the low point of one's life. The second, which we employed here, is examining stability and change 
in the way that a story is narrated, regardless of content. Both get at different ways of understanding how the stories we tell remain the same or change over time. In the case of our study, the examination of content was not possible because we asked for events from the last year. But studies that examine the repeated narration of the same event can provide complementary data on the question of how we remain the same and change at the level of narrative.

In sum, this is the first study designed to capture a contextualized picture of the process of personality development across the college years, with yearly assessments of distinct types of autobiographical reasoning in different domains, across a broad sample of college-going emerging adults at two distinct institutions. Consistent with theorizing in personality development, we see evidence for rank-order stability in autobiographical reasoning, providing further evidence for the role of narration as a level of personality. This kind of stability is particularly notable given that our participants were in a developmental stage defined by change (e.g., Arnett, 2000), and our assessments emphasized the contextual nature of their experiences. In terms of developmental change, there is change in the autobiographical reasoning across the college years, and the need for further multi-wave studies is needed. Further, our attention to distinct types of autobiographical reasoning provides evidence for how such constructs may be used depending on the research question at hand, with exploratory processing providing more information about narration more characteristic of the person, and self-event connections providing even more contextualized information about narration. Finally, our results speak to the role of domain and event type as important to understand the type and degree of autobiographical reasoning; that is, narration is not the same across types of experiences and 
Stability and Change in Autobiographical Reasoning 28

intra-individual variability in narration may be a fruitful path for those interested in narrative development over time. 


\section{References}

Adler, J.M. (2012). Living into the story: Agency and coherence in a longitudinal study of narrative identity development and mental health over the course of psychotherapy. Journal of Personality and Social Psychology, 102(2), 367-389. doi: 10.1037/a0025289

Adler, J. M. (2019). Stability and change in narrative identity: Introduction to the special issue on repeated narration. Qualitative Psychology, 6(2), 134-145. http://dx.doi.org/10.1037/qup0000155

Adler, J. M., Harmeling, L. H., \& Walder-Biesanz, I. (2013). Narrative meaning making is associated with sudden gains in psychotherapy clients' mental health under routine clinical conditions. Journal of Consulting and Clinical Psychology, 81(5), 839-845. https://doi.org/10.1037/a0033774

Adler, J.M., Lodi-Smith, J., Philippe, F.L., Houle, I. (2016). The incremental validity of narrative identity in predicting well-being: A review of the field and recommendations for the future. Personality and Social Psychology Review, 20(2), 142-175. doi:

\section{$10.1177 / 1088868315585068$}

Arnett, J. J. (2000). Emerging adulthood: A theory of development from the late teens through the twenties. American Psychologist, 55(5), 469-480. https://doi.org/10.1037/0003$\underline{066 X .55 .5 .469}$

Baxter Magolda, M. (2001). Making their own way: Narratives for transforming higher education to promote self-development. Sterling, VA: Stylus

Baxter Magolda, M. (2008). Three elements of self-authorship. Journal of College Student Development, 49, 269-284.

Booker, J. A., Brakke, K., Sales, J. M., \& Fivush, R. (2021). Narrative identity across multiple 
autobiographical episodes: Considering means and variability with well-being. Self and Identity, 1 - 24. https://doi.org/10.1080/15298868.2021.1895301

Borghuis, J., Denissen, J. J. A., Oberski, D., Sijtsma, K., Meeus, W. H. J., Branje, S., Koot, H. M., \& Bleidorn, W. (2017). Big Five personality stability, change, and codevelopment across adolescence and early adulthood. Journal of Personality and Social Psychology, 113(4), 641-657. https://doi.org/10.1037/pspp0000138

Caspi, A., Roberts, B.W., \& Shiner, R.L. (2005). Personality development: stability and change. Annual Review of Psychology, 56, 453-84. doi: 10.1146/annurev.psych.55.090902.141913.

Costa, P. T., Jr., \& McCrae, R. R. (1994). Stability and change in personality from adolescence through adulthood. In C. F. Halverson, Jr., G. A. Kohnstamm, \& R. P. Martin (Eds.), The developing structure of temperament and personality from infancy to adulthood (p. 139150). Lawrence Erlbaum Associates, Inc.

Dunlop, W. L., Guo, J., \& McAdams, D. P. (2016). The autobiographical author through time: Examining the degree of stability and change in redemptive and contaminated personal narratives. Social Psychological and Personality Science, 7(5), 428436. https://doi.org/10.1177/1948550616644654

Fivush, R., Booker, J. A., \& Graci, M. E. (2017). Ongoing narrative meaning-making within events and across the life span. Imagination, Cognition and Personality, 37(2), 127152. https://doi.org/10.1177/0276236617733824

Gahagan, J., \& Hunter, M. S. (2006). The second year experience: Turning attention to the academy's middle children. About Campus, 11(3), 17-22.

Habermas, T., \& Bluck, S. (2000). Getting a life: The emergence of the life story in adolescence. Psychological Bulletin, 126(5), 748-769. https://doi.org/10.1037/0033-2909.126.5.748 
Habermas, T., \& Reese, E. (2015). Getting a life takes time: The development of the life story in adolescence, its precursors and consequences. Human Development, 58(3), 172201. https://doi.org/10.1159/000437245

Habermas, T., \& de Silveira, C. (2008). The development of global coherence in life narratives across adolescence: Temporal, causal, and thematic aspects. Developmental Psychology, 44(3), 707-721. https://doi.org/10.1037/0012-1649.44.3.707

Jennings, S. C., Cruz Navas, G., Dalsimer, S., Radin, J., \& Lilgendahl, J. P. (2021). Centering student voices: A narrative approach to social identities, marginalization, and adjustment in college. Unbpublished Senior Thesis, Haverford College.

King, L. A., \& Raspin, C. (2004). Lost and Found Possible Selves, Subjective Well-Being, and Ego Development in Divorced Women. Journal of Personality, 72(3), 603632. https://doi.org/10.1111/j.0022-3506.2004.00274.x

King, L. A., Scollon, C. K., Ramsey, C., \& Williams, T. (2000). Stories of life transition: Subjective well-being and ego development in parents of children with Down Syndrome. Journal of Research in Personality, 34(4), 509-536. https://doi.org/10.1006/jrpe.2000.2285

Lilgendahl, J. P. (2015). The dynamic role of identity processes in personality development: Theories, patterns, and new directions. In K. C. McLean \& M. Syed (Eds.), Oxford library of psychology. The Oxford handbook of identity development (p. 490-507). Oxford University Press.

Lilgendahl, J. P., Dusold, O., Lee, A., Prinz, I., \& McLean, K. C. (2021). Is parental involvement controlling or supportive?: Perceptions of parenting and changes in student mental health in the transition to college. Manuscript in Preparation.

Lilgendahl, J. P., \& McAdams, D. P. (2011). Constructing stories of self-growth: How individual 
differences in patterns of autobiographical reasoning relate to well- being in midlife.

Journal of Personality, 79, 391-428. doi: 10.1111/j.1467-6494.2010.00688.x

Lilgendahl, J. P., \& McLean, K. C. (2020). Narrative identity processes and patterns of adjustment across the transition to college: A developmentally contextualized approach. Journal of Personality and Social Psychology, 119(4), 960977. https://doi.org/10.1037/pspp0000277

McAdams, D. P., \& Cox, K. S. (2010). Self and identity across the life span. In M. E. Lamb, A. M. Freund, \& R. M. Lerner (Eds.), The handbook of life-span development, Vol. 2. Social and emotional development (p. 158-207). New York: Wiley. https://doi.org/10.1002/9780470880166.hlsd002006

McAdams, D. P., Bauer, J. J., Sakaeda, A. R., Anyidoho, N. A., Machado, M. A., MagrinoFailla, K., White, K. W., \& Pals, J. L. (2006). Continuity and change in the life story: A longitudinal study of autobiographical memories in emerging adulthood. Journal of Personality, 74, 1371-1400. DOI:10.1111/j.1467-6494.2006.00412.x

McAdams, D. P., \& McLean, K. C. (2013). Narrative identity. Current Directions in Psychological Science, 22, 233-238. https://doi.org/10.1177/0963721413475622

McAdams, D. P., \& Pals, J. L. (2006). A new Big Five: Fundamental principles for an integrative science of personality. American Psychologist, 61, 204-217. DOI: 10.1037/0003- 066X.61.3.204

McLean, K. C., \& Breen, A. V. (2009). Processes and content of narrative identity development in adolescence: Gender and well-being. Developmental Psychology, 45(3), 702710. https://doi.org/10.1037/a0015207

McLean, K. C., Koeph, I. M., \& Lilgendahl, J. P. (2021). Identity Development and Major Choice Among Underrepresented Students Interested in STEM Majors: A Longitudinal Qualitative Analysis. Emerging Adulthood. https://doi.org/10.1177/21676968211015549 
McLean, K. C., \& Pasupathi, M. (2012). Processes of identity development: Where I am and how I got there. Identity: An International Journal of Theory and Research, 12(1), 828. https://doi.org/10.1080/15283488.2011.632363

McLean, K. C., Pasupathi, M., Fivush, R., Greenhoot, A. F., \& Wainryb, C. (2016). Does within person variability in narration matter and for what? Journal of Research in Personality, 69, 55 - 66. https://doi.org/10.1002/per.2279

McLean, K. C., Pasupathi, M., \& Pals. J. L. (2007). Selves creating stories creating selves: A process model of narrative self development in adolescence and adulthood. Personality and Social Psychology Review, 11, 262-278. https://doi.org/10.1177/1088868307301034

McLean, K. C., \& Riggs, A. E. (2021). No Age Differences? No Problem. Infant and Child Development.

McLean, K. C., Syed, M., Pasupathi, M., Adler, J. M., Dunlop, W.L., Drustrup, D., Fivush, R., Graci, M. E., Lilgendahl, J. L., Lodi-Smith, J., McAdams, D. P., \& McCoy, T. (2019). The Empirical Structure of Narrative Identity: The Initial Big Three. Journal of Personality: PPID, 119(4), 920-944. doi: 10.1037/pspp0000247.

McLean, K. C., Wood, R., \& Breen, A. (2013). Reflecting on a difficult life: Narrative construction and delinquency in vulnerable adolescents and the hazards of reflecting on difficult experiences. Journal of Adolescent Research, 28, 431-452. https://doi.org/10.1177/0743558413484355

de Moor, E.L., Van der Graaff, J., van Doeselaar, L., Klimstra, T.A. and Branje, S. (2021), With a little help from my friends? Perceived friendship quality and narrative identity in adolescence. Journal of Research on Adolescence, 31, 384- 401. https://doi.org/10.1111/jora.12605

Nelson, K., \& Fivush, R. (2004). The Emergence of Autobiographical Memory: A Social 
Cultural Developmental Theory. Psychological Review, 111(2), 486-

511. https://doi.org/10.1037/0033-295X.111.2.486

Pals, J. L. (2006). Narrative Identity Processing of Difficult Life Experiences: Pathways of Personality Development and Positive Self-Transformation in Adulthood. Journal of Personality, 64, 1079 - 1110. https://doi.org/10.1111/j.1467-6494.2006.00403.x

Patterson, A., Dunlap, D., Payne, N., Peterson, A., Tiemersma, K., Turner, K., Wolin, H., Lilgendahl, J. P., McLean, K. C. (2021). The Repeated Narration of the Transition to College. Manuscript in Preparation.

Pasupathi, M., Greenhoot, A. F., Fivush, R. \& McLean, K. C. (2020). Intra-individual Variability in Narrative Identity: Complexities, Garden Paths, and Untapped Research Potential. European Journal of Personality, 35(6), 1138-1150 https://doi.org/10.1002/per.2279

Pasupathi, M., \& Mansour, E. (2006). Adult age differences in autobiographical reasoning in narratives. Developmental Psychology, 42(5), 798-808. https://doi.org/10.1037/0012-1649.42.5.798

Pasupathi, M., Mansour, E., \& Brubaker, J. R. (2007). Developing a life story: Constructing relations between self and experience in autobiographical narratives. Human Development, 50, 85-110. doi:10.1159/000100939

Reese, E., Chen, Y., McAnally, H. M., Myftari, E., Neha, T., Wang, Q., \& Jack, F. (2014). Narratives and traits in personality development among New Zealand Māori, Chinese, and European adolescents. Journal of Adolescence, 37(5), 727-737. https://doi.org/10.1016/j.adolescence.2014.02.005

Roberts, B. W. (2007). Contextualizing personality psychology. Journal of Personality, 75(6), 1071-1082. https://doi.org/10.1111/j.1467-6494.2007.00467.x

Roberts, B. W., \& Wood, D. (2006). Personality Development in the Context of the Neo- 
Socioanalytic Model of Personality. In D. K. Mroczek \& T. D. Little (Eds.), Handbook of personality development (p. 11-39). Lawrence Erlbaum Associates Publishers.

Robins R.W., Fraley R.C., Roberts B.W., \& Trzesniewski K.H. (2001). A longitudinal study of personality change in young adulthood. Journal of Personality, 69(4), 617-40. doi: 10.1111/1467-6494.694157. PMID: 11497032.

Roberts, B. W., Walton, K. E., \& Viechtbauer, W. (2006). Patterns of mean-level change in personality traits across the life course: A meta-analysis of longitudinal studies. Psychological Bulletin, 132(1), 1-25. https://doi.org/10.1037/0033-2909.132.1.1

Sales, J.M., Merrill, N.A., \& Fivush, R. (2013) Does making meaning make it better? Narrative meaning making and well-being in at-risk African-American adolescent females. Memory, 21(1), 97-110. doi: 10.1080/09658211.2012.706614.

Singer, J. A. (2004). Narrative identity and meaning making across the adult lifespan: An introduction. Journal of Personality, 72, 437-459. DOI: 10.1111/j.0022- 3506.2004.00268.x

Syed, M., McLean, K.C. (2016). Understanding identity integration: Theoretical, methodological, and applied issues. Journal of Adolescence, 47, 109-18. doi: 10.1016/j.adolescence.2015.09.005.

Syed, M., \& Nelson, S. C. (2015). Guidelines for establishing reliability when coding narrative data. Emerging Adulthood, 3, 375-387. https://doi.org/10.1177/2167696815587648

Waters, T. E., Köber, C., Raby, K. L., Habermas, T., \& Fivush, R. (2019). Consistency and stability of narrative coherence: An examination of personal narrative as a domain of adult personality. Journal of Personality, 87(2), 151-162. DOI: $\underline{10.1111 / j o p y .12377}$ 
Table 1

Descriptive Statistics and Bivariate Correlations for Composite Exploratory Processing

\begin{tabular}{lllll}
\hline $\mathrm{n}=274-350$ & Mean(SD) & Year 1 & Year 2 & Year 3 \\
\hline Year 1 $(\mathrm{n}=437)$ & $1.52(.50)$ & - & & \\
Year 2 $(\mathrm{n}=409)$ & $1.61(.52)$ & $.43 * * *$ & -- & \\
Year 3 $(\mathrm{n}=336)$ & $1.60(.52)$ & $.44 * * *$ & $.51 * * *$ & -- \\
Year 4 $(\mathrm{n}=331)$ & $1.56(.46)$ & $.40 * * *$ & $.48^{* * *}$ & $.53 * * *$ \\
\hline$* *=\mathrm{p}<.001$ & & & &
\end{tabular}

Table 2

Descriptive Statistics and Bivariate Correlations for Academic Exploratory Processing

\begin{tabular}{lllll}
\hline $\mathrm{n}=274-350$ & Mean(SD) & Year 1 & Year 2 & Year 3 \\
\hline Year 1 $(\mathrm{n}=437)$ & $1.58(.59)$ & -- & & \\
Year 2 $(\mathrm{n}=409)$ & $1.65(.58)$ & $.37 * * *$ & -- & \\
Year 3 $(\mathrm{n}=336)$ & $1.60(.55)$ & $.38 * * *$ & $.39 * * *$ & - \\
Year 4 $(\mathrm{n}=331)$ & $1.59(.55)$ & $.30 * * *$ & $.40^{* * *}$ & $.50 * * *$ \\
\hline$* *=\mathrm{p}<.001$ & & & &
\end{tabular}

Table 3

Descriptive Statistics and Bivariate Correlations for Romantic Exploratory Processing

\begin{tabular}{lllll}
\hline $\mathrm{n}=220-286$ & Mean(SD) & Year 1 & Year 2 & Year 3 \\
\hline Year 1 $(\mathrm{n}=382)$ & $1.45(.55)$ & -- & & \\
Year 2 $(\mathrm{n}=363)$ & $1.57(.61)$ & $.29 * * *$ & - & \\
Year 3 $(\mathrm{n}=299)$ & $1.60(.60)$ & $.31 * * *$ & $.43 * * *$ & -- \\
Year 4 $(\mathrm{n}=290)$ & $1.54(.52)$ & $.32 * * *$ & $.29 * * *$ & $.38 * * *$ \\
\hline$* * *=\mathrm{p}<.001$ & & & &
\end{tabular}

Table 4

Descriptive Statistics and Bivariate Correlations ${ }^{+}$for Positive Composite Self-Event Connections

\begin{tabular}{lllll}
\hline $\mathrm{n}=350-274$ & Mean(SD) & Year 1 & Year 2 & Year 3 \\
\hline Year 1 $(\mathrm{n}=437)$ & $.26(.37)$ & - & & \\
Year 2 $(\mathrm{n}=409)$ & $.19(.26)$ & $.20^{* * *}(.22 * * *)$ & -- & \\
Year 3 $(\mathrm{n}=336)$ & $.19(.27)$ & $.19^{*}\left(.20^{* * *}\right)$ & $.20^{* * *}(.23 * * *)$ & -- \\
Year 4 $(\mathrm{n}=331)$ & $.14(.27)$ & $.15^{*}\left(.16^{* *}\right)$ & $.22 * * *\left(.20^{* * *}\right)$ & $.22 * * *(.27 * * *)$ \\
\hline
\end{tabular}

${ }^{+}$Spearman Rho in parentheses

$*=\mathrm{p}<.05 ; * *=\mathrm{p}<.01 ; * * *=\mathrm{p}<.001$ 
Table 5

Descriptive Statistics and Bivariate Correlations ${ }^{+}$for Positive Academic Self-Event Connections

\begin{tabular}{lllll}
\hline $\mathrm{n}=350-274$ & Mean(SD) & Year 1 & Year 2 & Year 3 \\
\hline Year 1 $(\mathrm{n}=437)$ & $.34(.47)$ & - & & \\
Year 2 $(\mathrm{n}=409)$ & $.29(.42)$ & $.28^{* * *}\left(.26^{* *}\right)$ & -- & \\
Year 3 $(\mathrm{n}=336)$ & $.27(.41)$ & $.11\left(.13^{*}\right)$ & $.19^{*}\left(.19^{* *}\right)$ & -- \\
Year 4 $(\mathrm{n}=331)$ & $.20(.37)$ & $.16^{* *}\left(.16^{* *}\right)$ & $.22^{* * *}\left(.21^{* * *}\right)$ & $.15^{*}\left(.20^{* * *}\right)$ \\
\hline
\end{tabular}

+ Spearman Rho in parentheses

$*=\mathrm{p}<.05 ; * *=\mathrm{p}<.01 ; * * *=\mathrm{p}<.001$

Table 6

Descriptive Statistics and Bivariate Correlations ${ }^{+}$for Positive Romantic Self-Event Connections

\begin{tabular}{lllll}
\hline $\mathrm{n}=286-220$ & Mean(SD) & Year 1 & Year 2 & Year 3 \\
\hline Year 1 $(\mathrm{n}=382)$ & $.21(.42)$ & -- & & \\
Year 2 $(\mathrm{n}=362)$ & $.13(.35)$ & $-.02(-.03)$ & -- & \\
Year 3 $(\mathrm{n}=298)$ & $.15(.33)$ & $.11\left(.13^{*}\right)$ & $.25^{* * *}\left(.27^{* *}\right)$ & -- \\
Year 4 $(\mathrm{n}=290)$ & $.10(.28)$ & $.02(-.00)$ & $.18^{* *}\left(.19^{* *}\right)$ & $.12\left(.14^{*}\right)$ \\
\hline
\end{tabular}

${ }^{+}$Spearman Rho in parentheses

$*=\mathrm{p}<.05 ; * *=\mathrm{p}<.01 ; * * *=\mathrm{p}<.001$

Table 7

Descriptive Statistics and Bivariate Correlations ${ }^{+}$for Negative Composite Self-Event Connections

\begin{tabular}{lllll}
\hline $\mathrm{n}=350-274$ & Mean(SD) & Year 1 & Year 2 & Year 3 \\
\hline Year 1 $(\mathrm{n}=437)$ & $.11(.23)$ & -- & & \\
Year 2 $(\mathrm{n}=409)$ & $.09(.24)$ & $.15(.12 *)$ & -- & \\
Year 3 $(\mathrm{n}=336)$ & $.07(.19)$ & $-.01(-.02)$ & $.69(.58)$ & -- \\
Year 4 $(\mathrm{n}=331)$ & $.09(.22)$ & $.07(.13 *)$ & $.19 * *(.12 *)$ & $.15 *(.11)$ \\
\hline
\end{tabular}

${ }^{+}$Spearman Rho in parentheses

$*=\mathrm{p}<.05 ; * *=\mathrm{p}<.01 ; * * *=\mathrm{p}<.001$

Table 8

Descriptive Statistics and Bivariate Correlations ${ }^{+}$for Negative Academic Self-Event Connections

\begin{tabular}{llllc}
\hline $\mathrm{n}=350-274$ & Mean(SD) & Year 1 & Year 2 & Year 3 \\
\hline Year 1 $(\mathrm{n}=437)$ & $.09(.22)$ & -- & & \\
Year 2 $(\mathrm{n}=409)$ & $.09(.27)$ & $.11^{*}(.09)$ & -- & - \\
Year 3 $(\mathrm{n}=336)$ & $.07(.21)$ & $-.03(-.02)$ & $.07(.07)$ & - \\
& & & & \\
Year 4 $(\mathrm{n}=331)$ & $.09(.26)$ & $.16^{* *}\left(.17^{* *}\right)$ & $.12^{*}(.07)$ & $.25^{* * *}\left(.13^{*}\right)$ \\
\hline
\end{tabular}

${ }^{+}$Spearman Rho in parentheses

$*=\mathrm{p}<.05 ; * *=\mathrm{p}<.01 ; * * *=\mathrm{p}<.001$

Table 9 
Stability and Change in Autobiographical Reasoning 38

Descriptive Statistics and Bivariate Correlations ${ }^{+}$for Negative Romantic Self-Event Connections

\begin{tabular}{lllll}
\hline $\mathrm{n}=286-220$ & Mean(SD) & Year 1 & Year 2 & Year 3 \\
\hline Year 1 $(\mathrm{n}=382)$ & $.12(.29)$ & -- & & \\
Year 2 $(\mathrm{n}=362)$ & $.08(.31)$ & $-.02(.00)$ & -- & \\
Year 3 $(\mathrm{n}=298)$ & $.05(.20)$ & $-.03(-.03)$ & $.25^{* * *}\left(.18^{* * *}\right)$ & - \\
Year 4 $(\mathrm{n}=290)$ & $.05(.18)$ & $.05(.06)$ & $-.05(-.06)$ & $.18^{* *}\left(.18^{* *}\right)$ \\
\hline
\end{tabular}

${ }^{+}$Spearman Rho in parentheses

$* *=\mathrm{p}<.01 ; * * *=\mathrm{p}<.001$ 


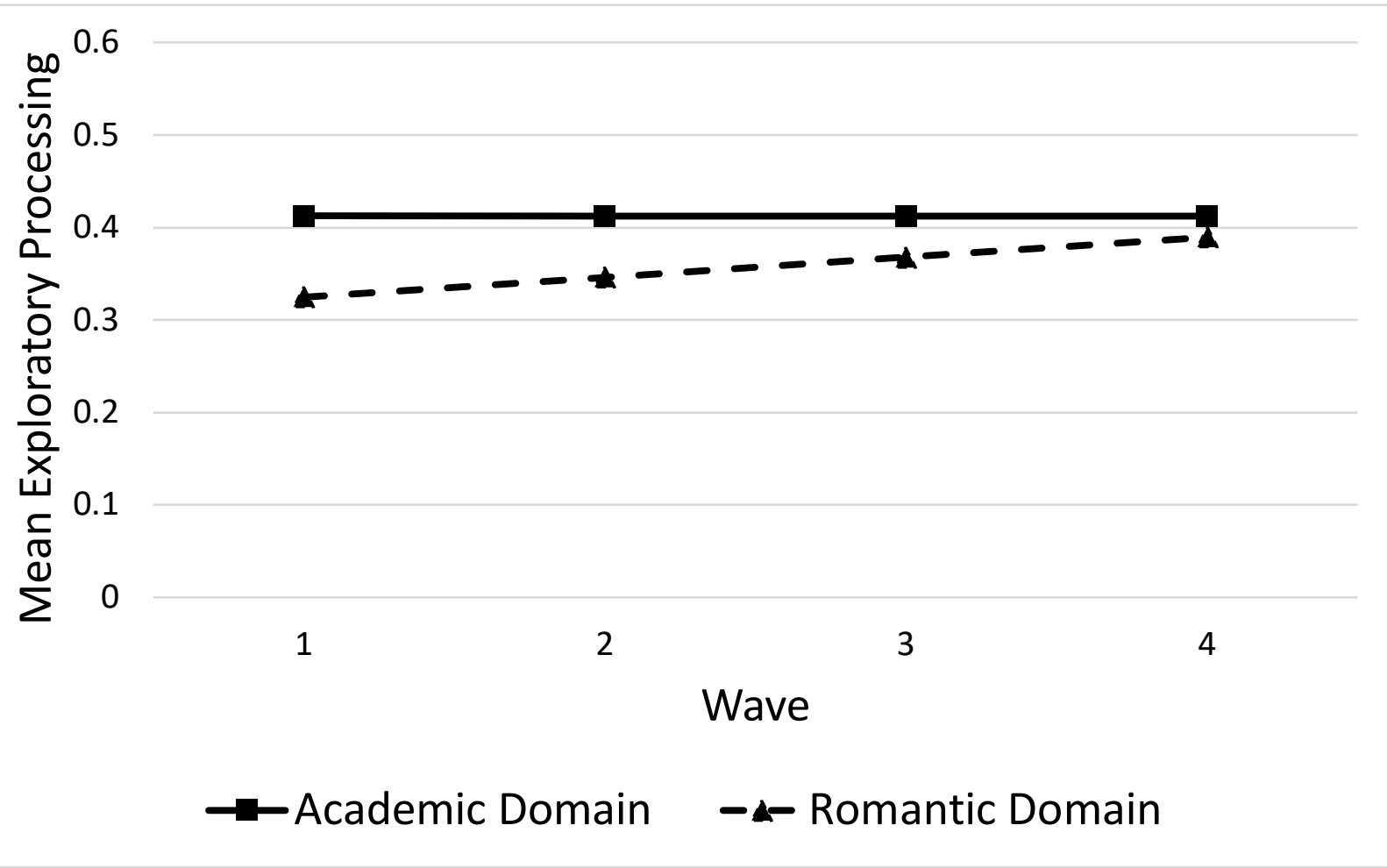

Figure 1. Fitted growth model for mean-level Changes in Exploratory Processing 


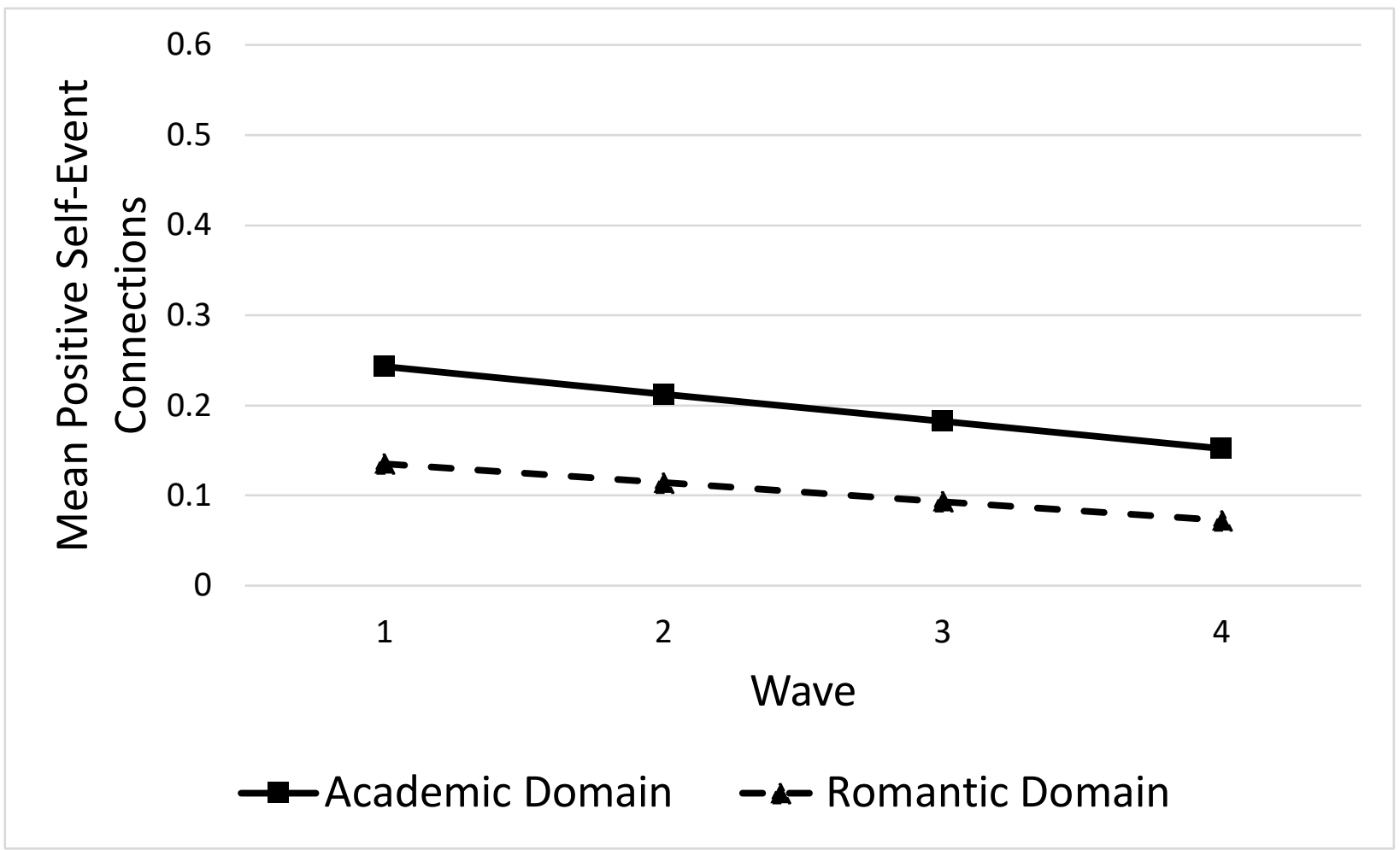

Figure 2. Fitted growth model for mean-level Changes in Positive Self-Event Connections 


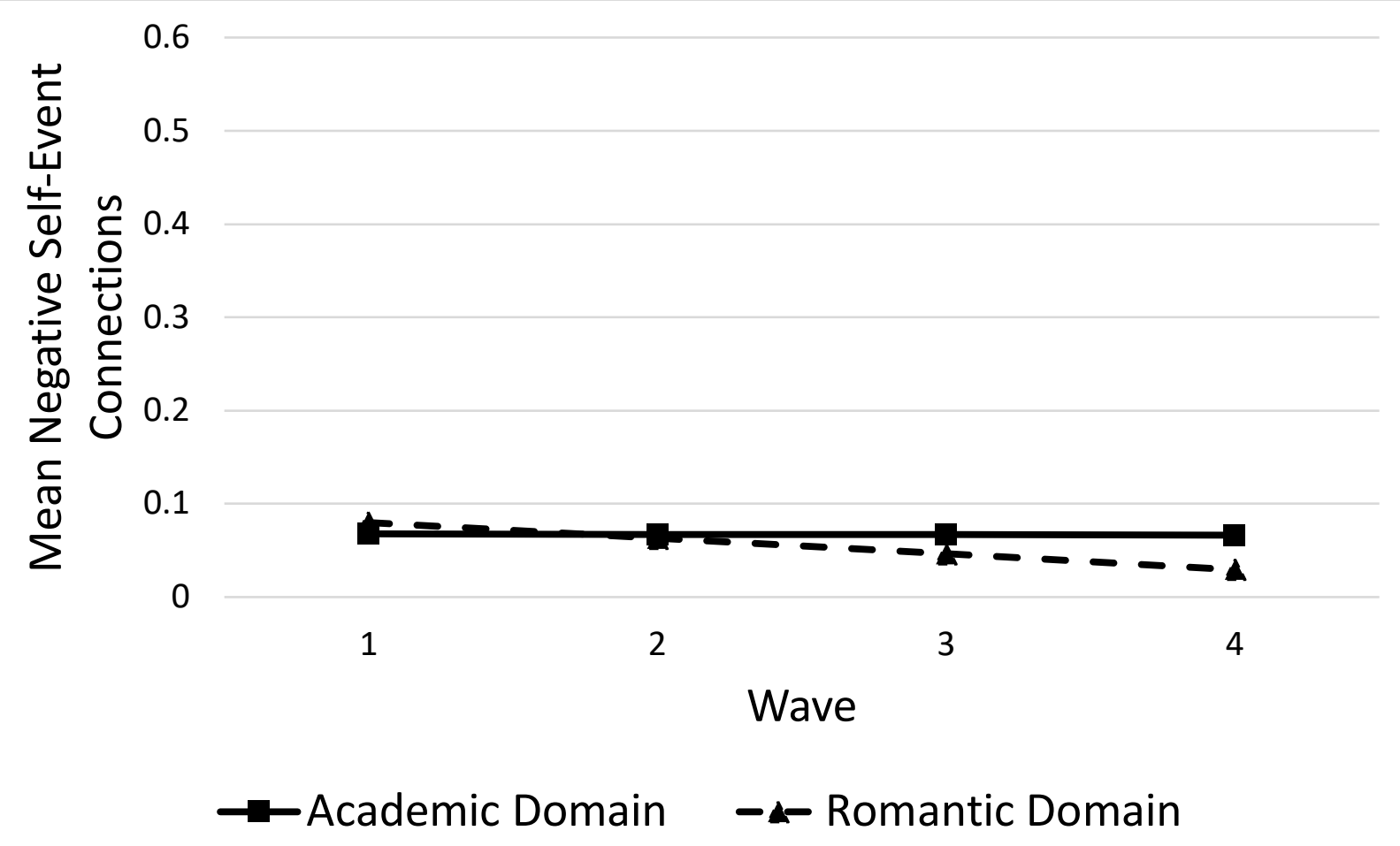

Figure 3. Fitted growth model for mean-level Changes in Negative Self-Event Connections 